\title{
EMBALAGEM ATIVA MULTIFUNCIONAL PARA A CONSERVAÇÃO DE PRODUTOS HORTÍCOLAS MINIMAMENTE PROCESSADOS
}

\author{
J. C. RAUSCHKOLB ${ }^{1}$, F. B. FORALOSSO ${ }^{2}$, N. FRONZA ${ }^{2}$ \\ ${ }^{1}$ Universidade Regional Integrada do Alto Uruguai e das Missões, Departamento de Engenharia \\ de Alimentos \\ ${ }^{2}$ Instituto Federal Catarinense, Departamento de Engenharia de Alimentos \\ E-mail para contato: jeancarlo_ab@hotmail.com
}

\begin{abstract}
RESUMO - Diversos alimentos são suscetíveis a ação de enzimas e micro-organismos, resultando na depreciação da qualidade, diminuição da vida útil, bem como consideráveis perdas econômicas. Por outro lado, diversos aditivos podem ser empregados para impedir tais alterações. Alguns destes aditivos são multifuncionais, capazes de retardar o desenvolvimento de micro-organismos, bem como a ação de enzimas, especialmente as que causam escurecimento em vegetais. Sendo assim, a presente pesquisa fundamentouse no estudo do processo de conservação de alimentos em seu estado natural com a utilização de embalagens ativas para a manutenção da qualidade dos alimentos por um tempo maior na prateleira, do que o naturalmente conseguido. A produção do filme consistiu na adição de metabissulfito de potássio misto (puro e encapsulado) à resina de PVC e sua aplicação em maçãs minimamente processadas para avaliar as potencialidades desta aplicação com relação a qualidade, segurança alimentar e aumento da vida-deprateleira do produto. $\mathrm{O}$ filme ativo desenvolvido manteve a qualidade e prolongou a vida útil de maças minimamente processadas, através do controle de micro-organismos e enzimas, garantindo sua segurança alimentar.
\end{abstract}

Palavras-chave: embalagem ativa, encapsulamento, residual de $\mathrm{SO}_{2}$, maçã minimamente processada, antiescurecimento, antimicrobiano.

DOI: $10.5965 / 24473650312017004$

\section{INTRODUÇÃO}

Atualmente, os consumidores buscam alimentos que apresentem praticidade e conveniência para consumo, que sejam frescos e saudáveis, atributos facilmente encontrados em vegetais minimamente processados (HARICH et al., 2017). Diversas estratégias para a conservação destes produtos são empregadas para a manutenção das características de qualidade e de segurança alimentar, com o aumento do período de comercialização. Por isso, o controle do escurecimento enzimático e o controle de micro-organismos indesejáveis são dois grandes desafios (FORALOSSO et al., 2013).

Este cenário oferece uma oportunidade para a indústria de embalagens oferecer soluções inovadoras para atender às demandas da indústria alimentar, dos consumidores e da legislação (REALINI, MARCOS, 2014). Assim, novas tecnologias de embalagens de alimentos, como as embalagens ativas, estão sendo desenvolvidas para aplicação no aumento da vida útil e na 
manutenção da qualidade (DOBRUCKA, CIERPISZEWSKI, 2014). A embalagem ativa é um sistema que permite a interação entre a embalagem, o produto e o ambiente (WYRWA, BARSKAL, 2017). Diversas substâncias podem ser utilizadas na composição da embalagem, porém poucas são eficazes no controle microbiológico simultaneamente à inibição do escurecimento enzimático em alimentos. Um aditivo multifuncional com propriedades antiescurecimento (XING et al., 2011) e antimicrobiana (MACHADO et al., 2006) é o metabissulfito de potássio (MBSK), o qual libera o gás $\mathrm{SO}_{2}$, permitindo a ação e o efeito no produto. Este agente pode ser incorporado aos filmes para contato com vegetais, porém sua resistência térmica para o processo de extrusão é baixa. Neste sentido, o processo de encapsulação do aditivo aumenta sua resistência térmica, preservando suas características, tornando sua incorporação em embalagens ativas uma técnica promissora (FORALOSSO et al., 2013).

Sendo assim, este estudo objetivou a avaliação de um filme ativo de Policloreto de vinila (PVC), com propriedades antiescurecimento e antimicrobianas pela adição de aditivo misto de MBSK (puro - MK e encapsulado - MKE), e seu efeito sobre parâmetros de qualidade de maçãs minimamente processadas.

\section{MATERIAIS E MÉTODOS}

Este trabalho foi realizado no Laboratório de Tecnologia de Vegetais e Embalagens do IFC - Campus de Concórdia.

Foram utilizadas maçãs cultivar Gala (Malus domestica Borkh), minimamente processadas através de processo tecnológico adequado.

O processo de encapsulação do aditivo seguiu a técnica sol-gel utilizando tetraetoxisilano (TEOS, 99\% Sigma-Aldrich, Brazil) e aminopropiltrietoxisilano (APTES, 98\% Merck, Brazil).

Foram produzidos filmes de PVC (Norvic ${ }^{\circledR}$ SP1000 Braskem) misturados com diferentes concentrações de aditivo misto contendo MK e MKE. O processo de extrusão foi conduzido em microextrusoraAXPlasticos ${ }^{\circledR}$, modelo AX 16L/D 26 com velocidade de rosca de $200 \mathrm{rpm}$, com temperatura para a zona 1 , de $120^{\circ} \mathrm{C}$, para a zona $2,140{ }^{\circ} \mathrm{C}$ e para a zona 3 de $160{ }^{\circ} \mathrm{C}$, com espessura nominal de 12 micra. A espessura dos filmes foi determinada utilizando-se um micrômetro Mainard ${ }^{\circledR}$ (precisão 0,001 mm; Modelo M 73011). Os valores de espessura foram obtidos através da média de cinco pontos de cada filme produzido. $\mathrm{O}$ ensaio foi conduzido em temperatura ambiente a cerca de $20^{\circ} \mathrm{C}$.

Para o estudo, foram estabelecidos quatro tratamentos: FC (controle), F01 (0,1\% p/p), F1 $(1,0 \%$ p/p) e F2 (2,0\% p/p), do aditivo misto (MK e MKE) em relação a massa do PVC.

Foram preparadas 360 unidades amostrais de maçãs minimamente processadas, em porções envolvidas nos diferentes filmes ativos, estocadas em diferentes tempos (zero, quatro, oito, doze, dezesseis e vinte dias de armazenamento) e condições de temperaturas de refrigeração e ambiente $\left(4^{\circ} \mathrm{C}, 8^{\circ} \mathrm{C}, 12^{\circ} \mathrm{C}, 16^{\circ} \mathrm{C}\right.$ e $\left.20^{\circ} \mathrm{C}\right)$, ambos em triplicata.

\subsection{Avaliação da vida-de-prateleira dos alimentos acondicionados no filme ativo}

As frutas foram adquiridas do comércio local do município de Concórdia - SC, através de processo tecnológico adequado, onde foramhigienizadas, descascadas, cortadas em pequenos cubos e envolvidas nos filmes ativos.

a) Avaliação do efeito antiescurecimento 
A determinação dos parâmetros de cor foi realizada em colorímetro MINOLTA (Color Reader, CR200), para calcular o índice de escurecimento (IE) de acordo com a equação descrita por Olivas et al. (2007):

$$
\text { IE }=[100(X-0,31)] / 0,172
$$

Onde: $\mathrm{X}=\left(\mathrm{a}^{*}+1,75 . \mathrm{L}^{*}\right) /\left[5,645 . \mathrm{L}^{*}+\mathrm{a}^{*}-\left(3,021 . \mathrm{b}^{*}\right)\right]$

b) Avaliação do efeito antimicrobiano

As amostras foram avaliadas quanto à contagem total de psicrotróficos (BRASIL, 2003).

c) Perda de massa durante estocagem

A perda de massa foi determinada por gravimetria e o resultado expresso em porcentagem de perda em relação à massa inicial (YAMASHITA et al., 2006).

d) Estudo da migração de $\mathrm{SO}_{2}$ para o produto

O teor residual de sulfito foi determinado por titulometria iodométrica (ARAUJO, 2008).

e) Análise estatística

Todas as análises estatísticas e cálculos de média e desvios-padrão foram realizados utilizandose o software Statistica versão 8 (Statsoft).

\section{RESULTADOS E DISCUSSÕES}

\subsection{Avaliação da vida-de-prateleira dos alimentos acondicionados no filme ativo}

a) Avaliação do efeito antiescurecimento

$\mathrm{O}$ efeito antiescurecimento nas amostras mostrado na Figura 1 indica que o IE foi maior para maçãs tratadas com os filmes FC e F01, diferindo dos demais Os tratamentos F1 e F2 foram estatisticamente iguais ( $p<0,05)$. Concentrações maiores de aditivos no filme apresentaram efetividade em relação à diminuição do escurecimento enzimático, devido a sua habilidade em reduzir $o$-quinonas geradas por enzimas, associada à redução da atividade enzimática destas, retornando-as ao composto fenólico de origem, impedindo formação de pigmentos escuros.

Referente à temperatura, esta não interferiu no índice de escurecimento, já que não foram encontradas diferenças significativas ( $p>0,05)$, no entanto verificou-se a influência do tempo sobre $o$ IE, ocorrendo aumento deste valor para todos os tratamentos ao longo do período de estudo. 


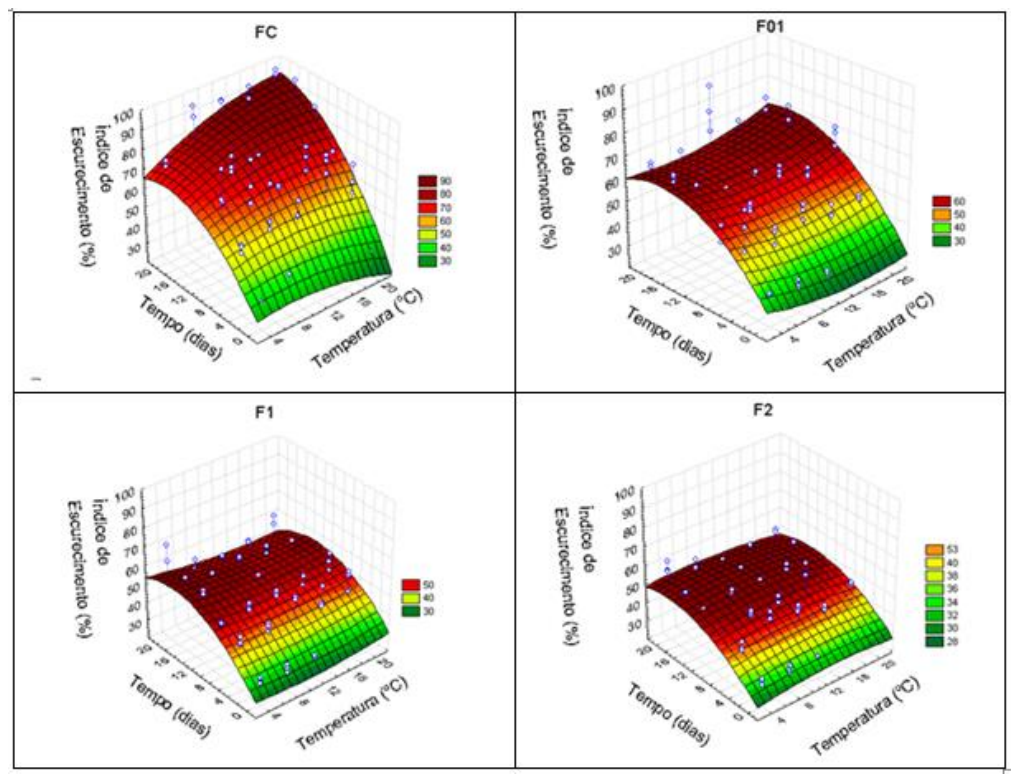

Figura 1 - Superfícies de respostas para o parâmetro IE em função do tempo e temperatura de armazenamento para os tratamentos FC, F01, F1 e F2. Acervo do autor (2013).

b) Avaliação do efeito antimicrobiano

A análise de variância para o parâmetro número de sobreviventes indicou que os tratamentos FC e F01 são iguais entre si ( $p>0,05)$, apresentando populações maiores. No entanto, eles são diferentes de F1 e F2 e estes também são diferentes entre si $(\mathrm{p}<0,05) \mathrm{O}$ menor número de sobreviventes foi encontrado no tratamento F2, de maior concentração de aditivo. O efeito inibitório do MBSK ocorre devido a presença dos íons sulfitos sobre o crescimento microbiano. Pelczar et al. (2005), descreve que os íons ou mesmo elementos puros, como por exemplo, metais dotados de carga negativa, inativam as proteínas celulares, combinando-se com algum componente da célula bacteriana. $\mathrm{O}$ ataque ocorre nos grupamentos sulfidrila da extremidade das proteínas, sendo estes ávidos por elétrons. Considerando-se o efeito de diferentes temperaturas sobre o crescimento microbiano, verificou-se uma forte influência sobre a taxa de crescimento $(p<0,05)$.

A Figura 2 reforça os resultados da análise de variância, uma vez que os resultados mostram que aumentando a temperatura e tempo de armazenamento, tem o aumento da população microbiana. O crescimento dos psicrotróficos foi elevado variando de 2,1 (tempo zero) a 8,2 log (tempo 20 dias) entre os tratamentos, em diferentes temperaturas, sendo superiores para os filmes FC e F01. 




Figura 2 - Superfícies de respostas para o parâmetro número de sobreviventes (log UFC.g $\mathrm{g}^{-1}$ ) em função do tempo e temperatura de armazenamento para os tratamentos FC, F01, F1 e F2. Acervo do autor (2013).

\section{c) Perda de massa durante a estocagem}

Nesse estudo, de maneira geral, foi possível afirmar que a perda de massa foi afetada pelos tratamentos, pelo período de armazenamento e temperatura, conforme podem ser observadas as superfícies de respostas da Figura 3. Os resultados indicaram maiores perdas para as maçãs acondicionadas nos filmes com concentrações maiores de aditivos (F1 e F2).

A incorporação do aditivo alterou significativamente a espessura dos filmes. Os resultados mostram um aumento significativo ( $\mathrm{p}<0,05)$ nos filmes ativos (F01, F1 e F2), que variaram de 8 a 17 $\mathrm{mm}$, proporcional ao aumento da concentração de aditivo incorporado em relação ao tratamento FC.

Através da análise de variância foi verificado que o tratamento F2 difere de todos os demais ( $p<0,01$ ), onde os maiores valores de perdas de massa foram encontrados (até $6,7 \%$ ). Foi verificada maior irregularidade na espessura destes filmes, adicionalmente ao acúmulo das partículas em certas regiões da matriz polimérica, já que as mesmas não apresentaram boa dispersão, aumentando a permeabilidade e consequentemente a perda de massa. 


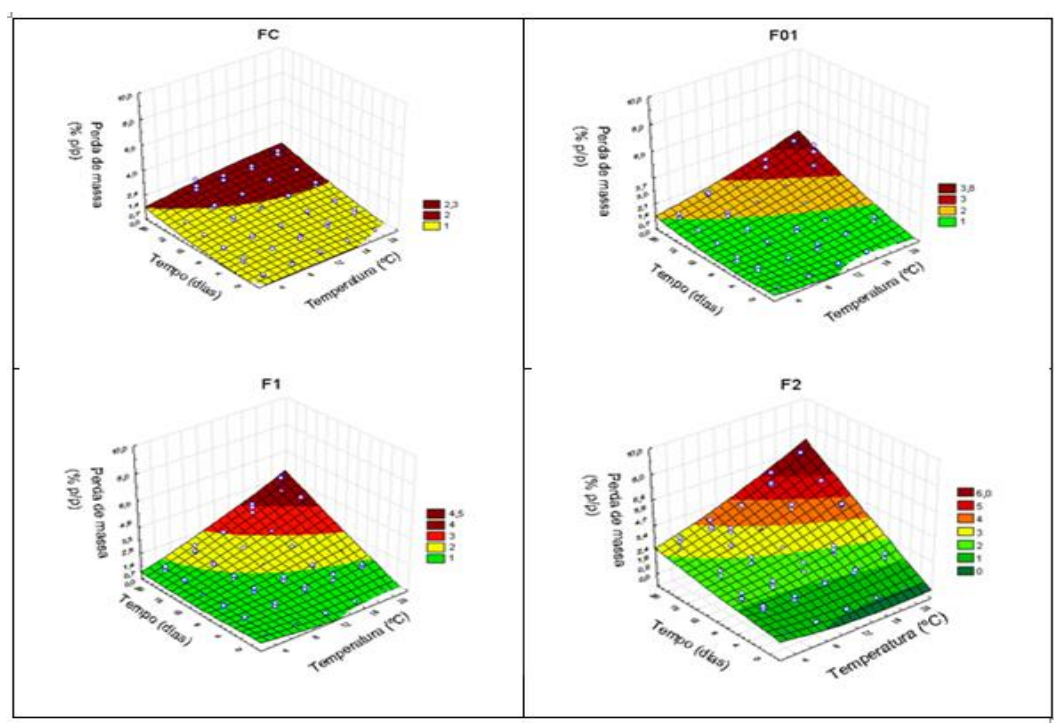

Figura 3 - Superfícies de respostas para o parâmetro perda de massa (PM) em função do tempo e temperatura de armazenamento para os tratamentos FC, F01, F1 e F2. Acervo do autor

(2013).

d) Estudo da migração de $\mathrm{SO}_{2}$ para o produto

A Figura 4 apresenta as superfícies de respostas para o parâmetro resíduo de $\mathrm{SO}_{2}$ em função do tempo e temperatura de armazenamento. Os resultados apresentaram-se bastante satisfatórios para os filmes F01 e F1 já que se encontram abaixo do limite permitido do aditivo $\mathrm{SO}_{2}$ em relação a polpas de frutas e da migração da embalagem para o alimento (10 mg. $\left.\mathrm{kg}^{-1}\right)$ (BRASIL, 2008), independente do tempo e da temperatura testados. Somente o filme F2 apresentou valores mais elevados, porém, acima de 16 dias de armazenamento à $12^{\circ} \mathrm{C}$.

Sendo assim, é possível demonstrar a importância da embalagem ativa que permite um controle do escurecimento com uma migração do sulfito menor do que o permitido pela legislação, diminuindo assim os níveis de sulfitos que serão ingeridos pelo consumidor, proporcionando conservação ao produto.

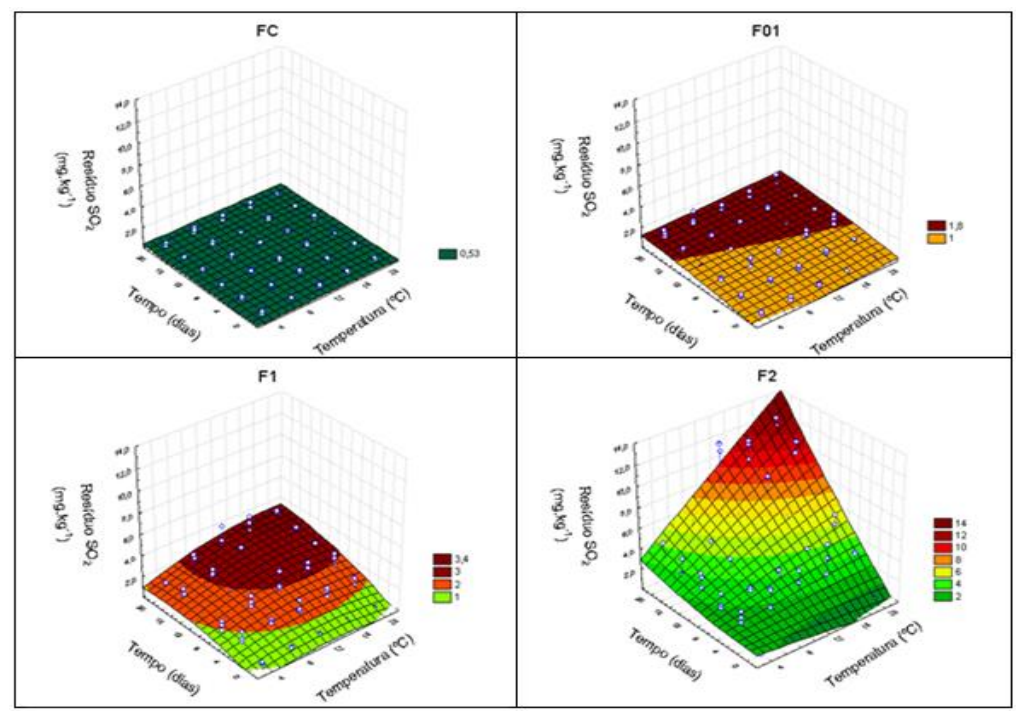

Figura 4 - Superfícies de respostas para o parâmetro resíduo de $\mathrm{SO}_{2}\left(\mathrm{mg}_{\mathrm{kg}} \mathrm{kg}^{-1}\right)$ em função do tempo e temperatura de armazenamento para os tratamentos FC, F01, F1 e F2. 


\section{CONCLUSÕES}

A análise das propriedades multifuncionais dos filmes ativos produzidos, apresentou efeito satisfatório para a manutenção da cor e qualidade microbiológica, bem como da segurança toxicológica em até 12 dias de análise à $8^{\circ} \mathrm{C}$ para o filme $\mathrm{F} 2$ apresentando condições próprias para consumo. Isto representa um aumento de até oito dias na vida de prateleira de maçãs cortadas.

Deste modo conclui-se que os filmes multifuncionais contendo ativos MK e MKE apresentamse como uma boa alternativa para o armazenamento de vegetais minimamente processados.

\section{REFERÊNCIAS}

ARAÚJO, J. M. A. Química de Alimentos: teoria e prática. 4, ed. Viçosa: UFV, 478 p. 2008.

BRASIL, Ministério da Agricultura, Pecuária e Abastecimento - MAPA. Instrução Normativa n62, de 26 de agosto de 2003. Métodos de Análise Microbiológica para alimentos e água.2003.

BRASIL. Ministério da Saúde. Agência Nacional de Vigilância Sanitária. Resolução da Diretoria Colegiada - RDC $\mathrm{n}^{\circ}$ 17, de 17 de março de 2008. Anexo Lista positiva de aditivos para materiais poliméricos destinada à elaboração de embalagens e equipamentos em contato com alimentos. 2008.

DOBRUCKA, R.; CIERPISZEWSKI, R. Active and Intelligent Packaging Food - Research and Development - A Review Polish Journal Food Nutrition Science., v. 64, n. 1, pp. 7-15, 2014.

FORALOSSO, F. B.; FRONZA, N.; ZIMNOCH, J. H.; CAPELETTI, L. B.; QUADRI, M. N. The Use of Duo-Functional PVC Film for Conservation of Minimally Processed Apples, Food Bioprocess Technology. DOI 10.1007/s11947-013-1233-2, 2013.

HARICH, M.; MAHERANI, B.; SALMIERI, E.; LACROIX, M. Antibacterial activity of cranberry juice concentrate on freshness and sensory quality of ready to eat (RTE) foods. Food Control, $v$ 75, p 134e144, 2017.

MACHADO, R. M. D.; TOLEDO, M. C. F. Sulfitos em alimentos. Brazilian Journal of Food Technology. v. 9, n. 4. p:265-275. out-dez. 2006.

OLIVAS, G. I.; MATTINSON, B. G. V. Alginate coating for preservation of minimally processed Gala apples. Postharvest Biology and Technology, v. 45, p. 89-96, 2007.

PELCZAR J. R. J. M.; CHAN, E.C.S.; KRIEG, N. R. Microbiologia: conceitos e aplicações. São Paulo: Makron Books, 2005.

REALINI, C. E.; MARCOS, B. Active and intelligent packaging systems for a modern society Meat Science. v. 98, p. 404-419, 2014.

XING, Y.; YUN, J.; LI, X., et al. The effect of formulation variables on the encapsulation efficiency and $\mathrm{SO}_{2}$-release behavior of microparticles containing sulphite. Advanced Materials Research. v. 152, 153, p: 512-515, 2011. 
WYRWA, J.; BARSKA, A. Innovations in the food packaging market: active packaging. European Food Research and Technology. October, v. 243, ed. 10, p. 1681-1692, 2017.

YAMASHITA, F.; VEIGA, G. F.; BENASSI, M. T.; ROBERTO, S. R. Morangos embalados com filme de Poli (cloreto de vinila) (PVC). Semina: Ciência Agrárias, Londrina, v. 27, n. 3, p: 429-436, jul/set, 2006. 